\title{
Pomza-Bazlı Adsorbanların Sentetik Su Numunelerinden Lityum Adsorpsiyonu Verimliliğinin Karşılaştırılması
}

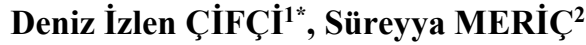 \\ ${ }^{1}$ Çevre Mühendisliği Bölmü, Çorlu Mühendsilik Fakültesi, Tekirdağ Namık Kemal Üniversitesi, Tekirdağ, Türkiye \\ ${ }^{2}$ Çevre Mühendisliği Bölmü, Çorlu Mühendsilik Fakültesi, Tekirdağ Namık Kemal Üniversitesi, Tekirdağ, Türkiye \\ ${ }^{* 1}$ dicifci@nku.edu.tr, ${ }^{2}$ smeric@nku.edu.tr
}

\begin{abstract}
Öz: Bu çalışmanın amacı kullanımı giderek artan ve değerli bir metal olan lityumun (Li) sulu çözelti içerisinde pomza adsorbanları ile geri kazanımının araştırılmasıdır. $\mathrm{Bu}$ amaç kapsamında manyetik demir kaplı pomza, $\mathrm{MnO}_{2}$ kaplı pomza ve Mn kaplı pomza malzemeleri hazırlanarak adsorpsiyon yöntemiyle Li giderimi karşılaştırılmıştır. Çalışmada ayrıca farklı sıcaklıkların, adsorpsiyon süresinin ve çözelti $\mathrm{pH}$ değerlerinin $\mathrm{Li}$ adsorpsiyonu üzerine etkisi de belirlenmiştir. $\mathrm{MnO}_{2} \mathrm{kapl}_{1}$ pomzanın SEM-EDX ve FTIR analizleri yapılarak özellikleri belirlenmiştir. Yapılan çalışma sonucunda demir kaplı pomza ile Li giderimi sağlanamasa da mangan kaplı pomzalar ile Li adsorpsiyonu gerçekleşmiştir. En yüksek giderimin sağlandığı $\mathrm{MnO}_{2}$ kaplı pomza ile yapılan çalışmalarda 1 saat adsorpsiyon süresinden sonra giderim veriminin değişmediğgi, sıcaklığın Li giderimine bir etkisinin olmadığı görülmüsstür. Fakat çözelti $\mathrm{pH}$ değeri lityum gideriminde önemli olup, en yüksek Li giderimi (\% 40) pH 9 değerinde elde edilmiştir. Bu giderim değeri düşük olmakla birlikte özellikle deniz suyundan tatlı su eldesi veya jeotermal sulardan Li kazanımı prosesleri için uygun ön arıtma alternatifi oluşturacaktır.
\end{abstract}

Anahtar kelimeler: Adsorpsiyon, lityum, mangan, pomza

\section{Comparision of Pumice-Based Adsorbents for Lithium Adsorption in Sythetic Aqueous}

\begin{abstract}
The aim of this study is to investigate the recovery of lithium (Li), which is a valuable rare earth element with an increasing consumption rate, by the adsorption process using different pumice-based adsorbents (magnetic iron coated pumice, $\mathrm{MnO}_{2}$ coated pumice and $\mathrm{Mn}$ coated pumice adsorbents) in distilled water. The effect of temperature, adsorption time and solution $\mathrm{pH}$ values on $\mathrm{Li}$ adsorption was studied. According to the results of the study, Li removal could not be achieved with iron coated pumice while Li adsorption occur with manganese coated pumice. The highest removal of Li was achieved with $\mathrm{MnO}_{2}$ coated pumice and it was observed that the removal efficiency did not change after $1 \mathrm{~h}$ adsorption time and the temperature did not affect Li removal. However, the $\mathrm{pH}$ of the solution was important in Li removal, and the highest Li removal was obtained at $\mathrm{pH} 9$. Although the removal efficiency was relatively low $(40 \%)$ these results can be evaluated as a good alternative for primary treatment to recover $\mathrm{Li}$ in membrane processes from seawater or geothermal waters.
\end{abstract}

Key words: Adsorption, lithium, manganese, pumice

\section{Giriş}

Lityum (Li) 31 nadir toprak metal elementlerinden biri olup, kullanımı arttıkça da daha değerli bir metal haline gelmektedir [1]. Yaygın olarak cep telefonları, dizüstü bilgisayarlar, tabletler gibi elektronik cihazların pillerinde kullanılan Li parfüm, plastik, ilaç endüstrisi gibi çeşitli alanlarda da kullanılmaktadır [2]. Lityum magmatik kayaçlar, tuzlu su gölü ve deniz suyu gibi farklı kaynaklardan elde edilebilmekte ancak deniz suyundan elde edilmesi oldukça maliyetli olmaktadır [3]. Ülkemizde farklı su ortamlarında yapılan ölçümlerde Li konsantrayonu 325 mg.L ${ }^{-1}$ (Tuz Gölü) - 20 mg.L. (Çanakkale Tuzla jeotermal sahasında) aralığında tespit edilmiştir [4].

Lityum geri kazanımı üzerine yapılan çalışmalarda adsorpsiyon, çökelme ekstraksiyonu, iyon değiştirici reçineler ve membran yöntemleri metotları kullanılmıştır [4-7]. Ancak Li iyon seçici memranlar ile Li gideriminde, lityumun adsorpsiyon ve desorpsiyonu kimyasal reaksiyon oranına bağlı olduğundan dolayı deniz suyundan Li gideriminde Li seçici membranların kullanılması uygun değildir [1]. Diğer yandan, adsorpsiyon yöntemi Li geri kazanımı için uygun ve ekonomik bir yöntem olarak ifade edilmiştir [5-6]. Lityum adsorpsiyonunda asit ve sodyum amberlit, aktif karbon, polimerik alüminyum hidroksit gibi adsorbanlar kullanılmıştır [7-9]. Ancak yapılan çalışmalarda $\mathrm{MnO}_{2}, \mathrm{LiMnO}_{2}$ veya $\mathrm{LiMn}_{2} \mathrm{O}_{4}$ yapısında bulunan ve iyon seçici özelliğe sahip Li iyon elekleri, ağırlıklı olarak kullanılmış ve başarılı sonuçlar elde edilmiştir [10-16]. Liu ve diğ. (2015) tarafindan yapılan

\footnotetext{
* Sorumlu yazar: dicifci@nku.edu.tr. Yazarların ORCID Numarası: ${ }^{1}$ 0000-0001-7527-6130, ${ }^{2}$ 0000-0002-2491-2755
} 
çalışmada, 0,2 g.L. $\mathrm{L}^{-1} \mathrm{MnO}_{2} \cdot 0,5 \mathrm{H}_{2} \mathrm{O}$ iyon seçici adsorban kullanılarak $\mathrm{pH} 10$ 'da 48 saat adsorpsiyon süresi sonunda Li adsorpsiyon kapasitesi 10,05 mg.g ${ }^{-1}$ olarak elde edilmiştir [10]. Ancak, iyon elek esaslı adsorbanların yüksek enerji gereksinimi ve düşük özgül yüzey alanına sahip olması gibi kısıtları bulunmaktadır. Bu nedenle, yüksek yüzey alanına sahip ve sentezi kolay adsorbanların geliştirilmesi gereklidir. Kamran ve diğ. (2019) tarafından yapılan çalışmada, $30 \mathrm{mg} . \mathrm{L}^{-1}$ giriş Li konsantrasyonu ve $\mathrm{pH} 12$ değerinde 60 dakika adsorpsiyon süresi sonunda $\mathrm{MnO}_{2}$ (0,1-0,2 $\mathrm{M} \mathrm{MnO}_{2}$ kaplama miktarında) kaplı aktif karbon adsorbanı ile 50,1-88,5 mg.g ${ }^{-1}$ aralığında Li adsorpsiyon kapasitesi elde edilmiştir [17].

Türkiye önemli pomza rezervine sahip olup, pomza hafif, yoğun gözenekli yapısı ile yüzey alanı fazla olan ve silisyum oksit içerikli volkanik bir taştır [18]. Pomza ayrıca adsorban malzemesi olarak ucuz olup, boya ve ağır metal adsorpsiyonunda yaygın olarak kullanılmaktadır [18]. Bu çalışmanın amacı, farklı kaplamalar ile hazırlanan pomza adsorbanlarının sentetik su numunelerinden Li adsorpsiyonu için kullanılabilirliğinin araştırılmasıdır. Bu kapsamda, manyetik demir kaplı pomza, $\mathrm{MnO}_{2}$ kaplı pomza ve $\mathrm{Mn}$ kaplı pomza malzemeleri hazırlanmıştır. Sıcaklık, pH, adsorpsiyon süresi gibi işletme parametrelerinin Li giderimine etkisi araştırılmıştır.

\section{Materyal ve Yöntem}

\subsection{Kullanılan kimyasallar}

Deneysel çalışmalarda kullanılan $\mathrm{NaOH}$ (Katalog No: 1.06462), $\mathrm{H}_{2} \mathrm{SO}_{4}$ (Katalog No: 1.09073), $\mathrm{MnSO}_{4} \cdot \mathrm{H}_{2} \mathrm{O}$ (Katalog No: 1.05941), $\left(\mathrm{NH}_{4}\right)_{2} \mathrm{~S}_{2} \mathrm{O}_{8}$ (Katalog No: 1.01200), FeSO $\mathrm{K}_{4} .7 \mathrm{H}_{2} \mathrm{O}$ (Katalog No: 1.03965) ve $\mathrm{FeCl}_{3} \cdot 6 \mathrm{H}_{2} \mathrm{O}$ (Katalog No: 1.03943) Merck firmasından temin edilmiştir. Çalışmalarda giriş Li konsantrasyonu ICP-OES cihazındaki ölçüm hassasiyeti gözönünde tutularak $25 \mathrm{mg} . \mathrm{L}^{-1}$ olarak seçilmiş olup, çözelti $\mathrm{LiNO}_{3}$ (Sigma Aldrich Katalog No: 227986) kullanılarak hazırlanmıştır.

\subsection{Pomza hazırlanışı}

Bu çalışmada adsorbent olarak kullanılan pomza tozu Nevşehir'den temin edilmiş olup, pomzanın partikül boyutu 0-125 mikron arasında değişmektedir.

\subsubsection{Manyetik demir kaplı pomzanın hazırlanışı}

Manyetik demir kaplı pomza hazırlamak için, ilk olarak $\mathrm{FeSO}_{4} \cdot 6 \mathrm{H}_{2} \mathrm{O}$ ve $\mathrm{FeCl}_{3} \cdot 6 \mathrm{H}_{2} \mathrm{O}$ kimyasalları $\mathrm{Fe}^{3+}$ ve $\mathrm{Fe}^{2+}$ molar oranları 2 olacak şekilde $200 \mathrm{~mL}$ distile suda çözünmüştür [19]. Daha sonra bu çözeltiye $100 \mathrm{~g}$ pomza ilave edilerek, pomzadaki demir oranı ağırlıkça \% 5 olacak şekilde ayarlanmıştır. Çözeltinin pH değeri 9.5 olacak şekilde $6 \mathrm{~N} \mathrm{NaOH}$ ilave edilmiş ve 15 dakika ultrasonikasyon uygulandıktan sonra, 1 saat $70{ }^{\circ} \mathrm{C}$ 'de karıştırılmıştır. 1 saat sonunda $5 \mathrm{~mL}$ amonyak çözeltisi (\% $30 \mathrm{v} / \mathrm{v})$ ilave edilmiştir. Çözelti 24 saat oda sıcaklığında karıştırılmıştır. 24 saat sonunda demir kaplanmış pomza birkaç defa distile su ile yıkanarak sülfat ve klorun pomzadan uzaklaştırılması ve $\mathrm{pH}$ değerinin nötr $\mathrm{pH}$ 'a ulaşması ayrıca da kaplanmayan demir metalinin pomzadan uzaklaştırılması sağlanmıştır. Daha sonra manyetik demir kaplı pomza tozu $105{ }^{\circ} \mathrm{C}$ 'de etüvde 24 saat kurutulmuştur.

\subsection{2. $\mathrm{MnO}_{2}$ kaplı pomzanın hazırlanışı}

$\mathrm{MnO}_{2}$ kaplama prosedürü için literatürde Zhang ve diğ. (2007; 2009) tarafından yapılan çalıșmalar esas alınmış, hazırlanışı sırasında bazı değişiklikler yapılmıştır [12-13]. $\mathrm{MnSO}_{4} \cdot \mathrm{H}_{2} \mathrm{O}(9,72 \mathrm{~g})$ ve $\left(\mathrm{NH}_{4}\right)_{2} \mathrm{~S}_{2} \mathrm{O}_{8}(13,12 \mathrm{~g})$ $100 \mathrm{~mL}$ distile suya eklenerek $6 \mathrm{~N} \mathrm{NaOH}$ ile pH 10 değerine ayarlanmıştır. Daha sonra otoklavda $120^{\circ} \mathrm{C}$ 'de 20 dakika (3 kez) otoklavlanmış ve takiben $120{ }^{\circ} \mathrm{C}$ 'de 6 saat karıştırılmıştır. $\mathrm{MnO}_{2}$ partikülü filtreden süzülerek ayrılmış ve distile su ile yıkanmıştır. Daha sonra pomza (100 gr) $250 \mathrm{~mL}$ distile suya konularak $\mathrm{MnO}_{2}$ partikülü ile karıştırılmış ve $6 \mathrm{~N} \mathrm{NaOH}$ ilave edilerek pH 10'a ayarlanmıştır. Karışım $70{ }^{\circ} \mathrm{C}$ 'de 1 saat ve oda sıcaklığında 24 saat karıştırılmıştır. Daha sonra filtre ile süzülerek $\mathrm{MnO}_{2}$ kaplı pomza distile su ile yıkanmıştır. $\mathrm{MnO}_{2}$ kaplı pomza $105{ }^{\circ} \mathrm{C}$ 'de 24 saat kurutulduktan sonra $500{ }^{\circ} \mathrm{C}$ 'de 1 saat aktive edilmiştir. 


\subsubsection{Mn kaplı pomzanın hazırlanıșı}

İlk olarak $\mathrm{MnSO}_{4} \cdot \mathrm{H}_{2} \mathrm{O} 200 \mathrm{~mL}$ distile suda çözünmüştür. Daha sonra bu çözelti içerisine $100 \mathrm{~g}$ pomza ilave edilmiştir. Pomza içerisindeki mangan oranı ağırlıkça $\% 5$ olacak şekilde ayarlanmıştır. Çözeltinin $\mathrm{pH}$ değeri 9,5 olacak şekilde $6 \mathrm{~N} \mathrm{NaOH}$ ilave edilmiştir. Çözeltiye 15 dakika ultrasonikasyon uygulandıktan sonra, 1 saat 70 ${ }^{\circ} \mathrm{C}$ 'de karıştırılmıştır. 1 saat sonunda çözelti soğuduktan sonra $5 \mathrm{~mL}$ amonyak çözeltisi (\% $30 \mathrm{v} / \mathrm{v}$ ) ilave edilmiştir. Çözelti 24 saat oda sıcaklığında karıştırıldıktan sonra birkaç defa distile su ile yıkanarak sülfat ve persülfatın pomzadan uzaklaştırılması ve $\mathrm{pH}$ değerinin nötr $\mathrm{pH}$ 'a ulaşması ayrıca da kaplanmayan mangan metalinin pomzadan uzaklaştırılması sağlanmıştır. Daha sonra mangan kaplı pomza $105^{\circ} \mathrm{C}$ 'de etüvde 24 saat kurutulmuştur.

\subsection{Adsorpsiyon çalıșmaları}

Adsorpsiyon çalışmalarında lityumun farklı pomzalar ile gideriminde sıcaklık ve süre etkisinin belirlenmesi amacı ile 20 ve $35^{\circ} \mathrm{C}$ sicaklıklarda Mn kaplı pomza ve $\mathrm{MnO}_{2}$ kaplı pomza ile 1 saat, 4 saat ve 24 saat adsorpsiyon sürelerinde Li giderimi belirlenmiştir. Pomza ve manyetik demir kaplı pomza için ise $25^{\circ} \mathrm{C}$ sıcaklıklarda 3,5 saat ve 12 saat adsorpsiyon sürelerinde Li giderimi belirlenmiştir. Her bir erlen içerisine $2,5 \mathrm{~g}$ pomza ve $100 \mathrm{~mL} 25$ mg. $\mathrm{L}^{-1} \mathrm{Li}$ çözeltisi eklenmiştir. $\mathrm{H}_{2} \mathrm{SO}_{4}$ ve $\mathrm{NaOH}$ kullanılarak numunelerin $\mathrm{pH}$ değeri 7 'ye ayarlanmış ve çalkalayıcıya konularak $125 \mathrm{rpm}$ hızda 1 saat çalkalama yapılmıştır. Çalkalama sonrasında numuneler filtre ile süzülerek Mn-Pomzanın çözelti içerisinden ayrılması sağlanmıştır. ICP-OES cihazı ile numunelerin Li konsantrasyonları belirlenmiştir.

Daha sonra lityum gideriminde $\mathrm{pH}$ etkisinin araştırıldığ çalışmada, her bir erlen içerisine 2,5 g Mn kaplı pomza veya $\mathrm{MnO}_{2}$ kaplı pomza konularak, $100 \mathrm{~mL} 25 \mathrm{mg} . \mathrm{L}^{-1} \mathrm{Li}$ çözeltisi eklenmiştir. Erlen içerisindeki numuneler $1 \mathrm{~N} \mathrm{H}_{2} \mathrm{SO}_{4}$ ve $1 \mathrm{~N} \mathrm{NaOH}$ kullanılarak pH metre (WTW 315i) yardımı ile $\mathrm{pH} 3,5,7$ ve 9 değerlerine ayarlanmıștır. Numuneler Nüve ST30 1sıtmalı çalkalayıcıya konularak, $35{ }^{\circ} \mathrm{C}$ sıcaklıkta ve $125 \mathrm{rpm}$ hız ile 1 saat çalkalama yapılmıştır. Çalkalama sonrasında numuneler filtre ile süzülerek $\mathrm{Mn}$ ve $\mathrm{MnO}_{2}$ kaplı pomzanın çözelti içerisinden ayrılması sağlanmıştır. ICP-OES cihazı ile numunelerin Li konsantrasyonları belirlenmiştir.

Deneysel çalışmalarda manyetik demir kaplı pomza ile lityum adsorpsiyonunda bir giderim elde edilemediğinden manyetik demir kaplı pomza miktarı arttırılarak farklı $\mathrm{pH}$ değerlerinde adsorpsiyon çalışması gerçekleştirilmiştir. Bu çalışmada her bir erlen içerisine 7,5 g manyetik demir kaplı pomza konularak, erlene 25 mg. $\mathrm{L}^{-1} \mathrm{Li}$ konsantrasyonuna sahip $100 \mathrm{~mL}$ çözeltisi eklenmiştir. Erlen içerisindeki numuneler $\mathrm{H}_{2} \mathrm{SO}_{4}$ ve $\mathrm{NaOH}$ kullanılarak pH metre (WTW 315i) yardımı ile $\mathrm{pH}$ 3, 4, 5, 8 ve 11,5 değerlerine ayarlanmıştır. Numuneler Nüve ST30 ssıtmalı çalkalayıcıya konularak, $25^{\circ} \mathrm{C}$ sıcaklıkta ve $125 \mathrm{rpm}$ hız ile 1 saat çalkalama yapılmıştır. Çalkalama sonrasında numuneler filtre ile süzülerek $\mathrm{Mn}$ ve $\mathrm{MnO}_{2}$ kaplı pomzanın çözelti içerisinden ayrılması sağlanmıştır. ICP-OES cihazı ile numunelerin Li konsantrasyonları belirlenmiştir.

\subsection{Analizler}

Adsorpsiyon deneylerinde en iyi giderimin sağlandığı $\mathrm{MnO}_{2}$ kaplı pomzanın karakterizasyonu yapılmıştır. Buna göre, yüzey görüntüsü ve kaplama oranlarının belirlenmesi amacıyla SEM-EDX (FEI marka QUANTA FEG 250 model) analizi yapılmıştır. $\mathrm{MnO}_{2}$ kaplı pomzanın FTIR analizi $400-4000 \mathrm{~cm}^{-1}$ aralığında Bruker (Vertex 70 ATR) cihazında yapılmıştır. Çalışmalarda Li analizi SpectroBlue marka ICP-OES cihazı ile yapılmıştır. Ayrıca $\mathrm{MnO}_{2}$ kaplı pomza ve Mn kaplı pomzanın adsorpsiyon sırasında kaplı olan Mn'nin çözünürlügünün belirlenmesi için de çözelti içerisindeki Mn konsantrasyonu aynı cihaz ile ölçülmüştür.

\section{Deneysel Sonuçlar}

\subsection{Farklı pomza adsorbanları kullanılarak elde edilen Li giderimi: adsorpsiyon süresi ve sıcaklığın etkisi}

Pomza, manyetik demir kaplı pomza ve $\mathrm{MnO}_{2}$ kaplı pomza kullanılarak yapılan Li giderimi çalışmalarında elde edilen Li giderimleri Şekil 1'de verilmiştir. Buna göre, $25^{\circ} \mathrm{C}$ 'de pomza ve manyetik demir kaplı pomza ile 12 saat adsorpsiyon süresine kadar önemli bir Li giderimi elde edilememiştir. $\mathrm{MnO}_{2}$ kaplı pomza kullanılarak yapılan çalışmada ise 24 saat adsorpsiyon süresine kadar deneysel çalışmalar gerçekleştirilmiş̧tir. Ancak 1 saat adsorpsiyon süresinden sonra Li gideriminde bir değişim gözlenmemiştir. $20^{\circ} \mathrm{C}$ ve $35^{\circ} \mathrm{C}$ olmak üzere 2 farklı sabit sıcaklık uygulanarak yapılan adsorpsiyon çalışmalarında da sıcaklığın Li giderimi üzerinde önemli bir 
etkisinin olmadığı görülmektedir. Myai ve diğ. (1988) tarafından $\mathrm{HMnO}(\mathrm{Mg})$ adsorbanı ile yapılan çalışmada da $5-35^{\circ} \mathrm{C}$ sıcaklık aralığından Li gideriminde önemli bir değişim olmadığı kaydedilmiştir [20].

$\mathrm{MnO}_{2}$ kaplı pomza kullanılarak 1 saat adsorpsiyon sonunda Li giderimi \%29,2 olarak elde edilmiştir. Elde edilen sonuçlar neticesinde pomza ile Li giderimi gözlenmezken, pomza kaplamaları çalışmalarında da demirin bir etkisinin olmadığı ancak mangan kaplamasının Li giderimini arttırdığ görülmektedir.

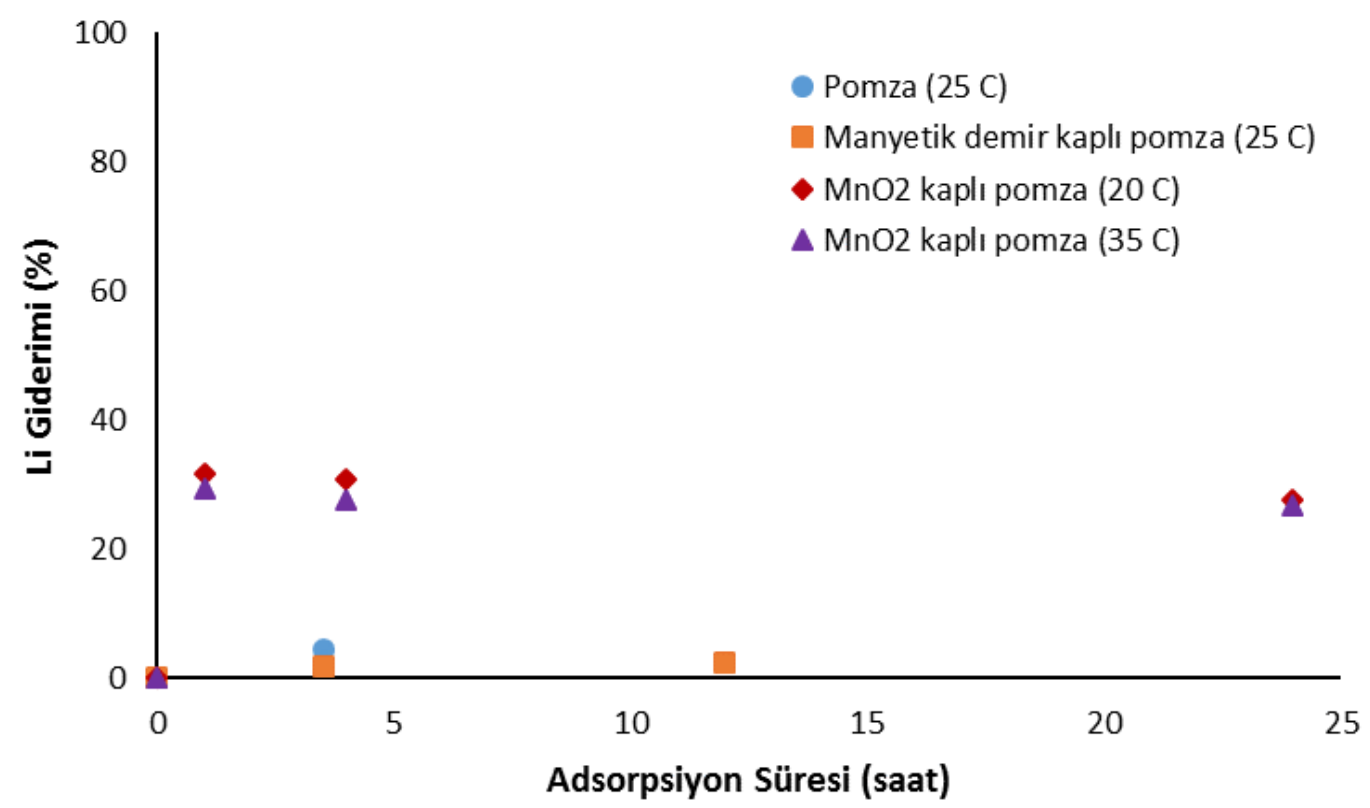

Şekil 1. Farklı pomza adsorbanları kullanılarak elde edilen Li giderimi (Başlangıç Li konsantrasyonu: 25 mg. $\mathrm{L}^{-1}$, çalkalama hızı: $125 \mathrm{rpm}$, pomza miktarı: 2,5 g/100 mL, pH 7)

\subsection{Farklı Mn kaplı pomzalar ile farklı pH değerlerinde elde edilen Li giderimi}

$\mathrm{MnO}_{2}$ ve Mn kaplı pomza kullanılarak farklı $\mathrm{pH}$ değerlerinde, 1 saat adsorpsiyon süresi sonunda elde edilen Li giderimleri Şekil 2'de verilmiştir. Şekil 2'de görüldüğü üzere pH 3 ve 5 gibi asidik koşullarda Li giderimi gözlenmezken, $\mathrm{pH} 7$ değerinden sonra Li giderimi gözlenmeye başlamıştır. $\mathrm{pH} 9$ değerinde ise Li giderimi artmaya başlamış ancak pH 11 değerinde ise önemli bir değişim elde edilmemiştir. Benzer şekilde Miyai ve diğ. (1988) tarafından $\mathrm{HMnO}(\mathrm{Mg})$ adsorbanı kullanılarak yapılan çalışmada, $170 \mu \mathrm{g} . \mathrm{L}^{-1}$ giriş Li konsantrasyonunda 4 gün adsorpsiyon suresi ve pH değeri 4'te Li adsorpsiyonu gözlenmez iken, pH değeri 8,9'a kadar arttırıldığında Li adsorpsiyonunun 5,6 mg. $\mathrm{g}^{-1}$ değerine arttı̆̆ görülmüştür [20]. Yine Park ve diğ. (2015) HMnO adsorbanı ile 20 mg. $\mathrm{L}^{-1}$ giriş Li konsantrasyonunda 2 gün adsorpsiyon süresi ve $\mathrm{pH}$ değeri 10'a kadar arttırıldığında Li gideriminde artış gözlenmiştir [21]. $\mathrm{pH}$ arttıkça Li adsorpsiyonunun artmasının sebebi, $\mathrm{MnO}_{2}$ kaplı pomzanın yüzey yükünün daha fazla negatif yüklenmesi ve pozitif yüklü olan Li elementi ile adsorban arasındaki elektrostatik çekici gücün artmasından kaynaklanmaktadır [21].

$\mathrm{MnO}_{2}$ ve $\mathrm{Mn}$ kaplı pomza adsorbanları karşılaştırıldığında ise $\mathrm{MnO}_{2}$ kaplı pomza adsorbanının Li gideriminde daha etkili olduğu görülmektedir. En yüksek Li giderimi pH 9 değerinde $\mathrm{MnO}_{2}$ ve $\mathrm{Mn}$ kaplı pomza adsorbanları kullanılarak sırasıyla \%37,2 ve \%19,6 olarak gözlenmiştir (Şekil 2).

Çözelti içerisindeki Mn konsantrasyonu ölçüm sonuçları incelendiğinde, $\mathrm{pH} 3$ değerinde Mn'nin çözünürlüğü yüksek (12,57 ppm) olup pomza üzerindeki Mn’nin çözünürlüğü artmıştır. pH 7 ve pH 9 değerlerinde ise çözünen Mn konsantrasyonu Mn kaplı pomza için sırasıyla 1,69 ve 1,82 ppm iken, $\mathrm{MnO}_{2}$ kaplı pomza için ise sırasıyla 1,02 ve 1,05 ppm olarak ölçülmüştür. Sonuçlara bakıldığında $\mathrm{MnO}_{2}$ kaplı pomzanın Li adsorpsiyon verimi daha yüksek ve Mn çözünürlük miktarının ise daha düşük olduğu görülmüştür (Şekil 2). 
Deniz İzlen Çíḟ̧̧, Süreyya MERİ̧

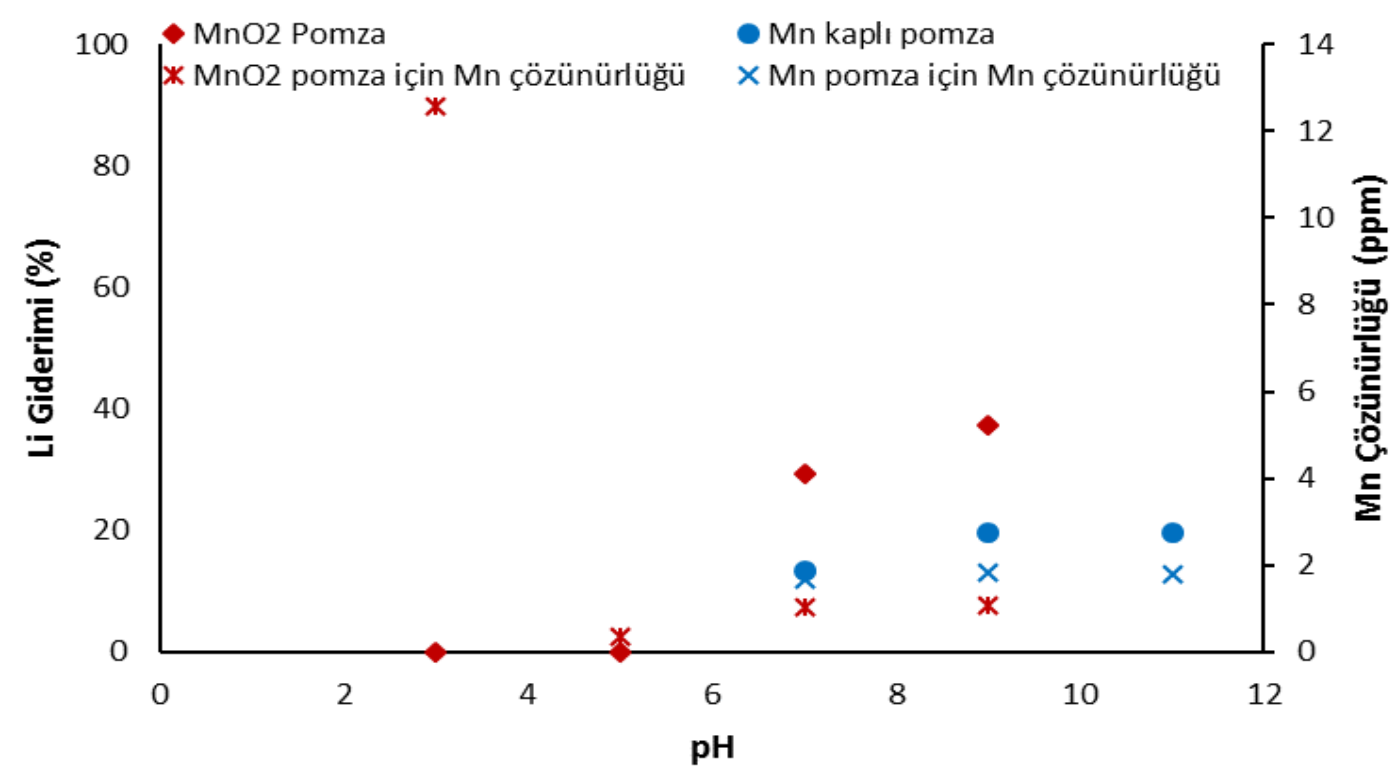

Şekil 2. $\mathrm{MnO}_{2}$ ve $\mathrm{Mn}$ kaplı pomza adsorbanları kullanılarak elde edilen Li giderimi (Başlangıç Li konsantrasyonu: $25 \mathrm{mg} . \mathrm{L}^{-1}$, sıcaklık: $35^{\circ} \mathrm{C}$, çalkalama hızı: $125 \mathrm{rpm}$, pomza miktarı: $2,5 \mathrm{~g} / 100 \mathrm{~mL}$, adsorpsiyon süresi: 1 saat)

\subsection{Manyetik demir kaplı pomzalar ile farklı pH değerlerinde elde edilen Li giderimi}

Günan Yücel (2017) Li iyonlarının sulu çözeltilerden yaş, kuru ve ön işleme tabi tutulmuş Pichia stipitis maya hücrelerine ve bu maya hücrelerinin aktif karbonla demir(III) varlığında muamele edilmesiyle elde edilen hibrit adsorbente adsorpsiyonunu incelemiştir [22]. Uygulanan ön işlemlerin mayaların Li adsorpsiyon kapasitesini arttıramadığı belirlenmiş ve yaş ve kuru maya hücreleri ile ticari aktif karbonla demir(III) varlığında hibrit adsorbent oluşturularak Li adsorpsiyonu çalışılmıştır. Buna göre, en uygun hibrit adsorbent üretim koşulları, muamele öncesi başlangıç pH'ı 9,5'e ayarlanmış sulu ortamda, 2 g.L. $\mathrm{L}^{-1}$ kuru hücre+0,3 g.L ticari aktif karbon+0,072 g.L $\mathrm{L}^{-1}$ demir(III)'in 85 rpm'de karıştırılması olarak belirlenmiştir. Her üç adsorbent için de $\mathrm{pH} 10^{\prime} \mathrm{da}$ en yüksek Li adsorpsiyon kapasitesi elde edilmiş, başlangıç Li derişiminin 50 mg. $\mathrm{L}^{-1}$ 'ye kadar arttırılmasıyla Li adsorpsiyon kapasitesinin arttı̆̆ kapasitesinin azaldığı görülmüştür. pH 10’da 50 mg.L ${ }^{-1}$ başlangıç Li derişiminde, 2-2,3 g.L $\mathrm{L}^{-1}$ adsorbent derişiminde en yüksek adsorpsiyon kapasite değerleri yaş maya hücreleri için 1,06 mg.g $\mathrm{g}^{-1}\left(134,1 \mu \mathrm{mol} . \mathrm{g}^{-1}\right)$, kuru maya hücreleri için 1,24 mg.g $\mathrm{g}^{-1}\left(178,1 \mu \mathrm{mol} \cdot \mathrm{g}^{-1}\right)$ ve hibrit adsorbent için 1,70 mg.g $\mathrm{g}^{-1}\left(245,3 \mu \mathrm{mol} . \mathrm{g}^{-1}\right)$ olarak belirlenmiştir. Kuru maya hücrelerine ve hibrit adsorbente adsorplanan Li iyonlarının \%100 verimle desorplandığı ve bu adsorbentlerin ardarda beş kez kullanılabileceği gösterilmiştir.

Bu çalışmada, adsorpsiyon sonrası demirin ortamdan kolayca ayrılmasını sağlamak üzere demir kaplı pomza ile yapılan adsorpsiyon çalışmaları yapılmış, ancak Li giderimi verimli elde edilememiştir. Pomza miktarı 7,5 g (100 mL çözelti) ve farklı pH değerlerinde adsorpsiyon çalışması sonuçları Tablo 1'de görülmektedir.

Tablo 1. Manyetik demir kaplı pomza ile farklı pH değerlerinde elde edilen Li giderimi (Başlangıç Li konsantrasyonu: $25 \mathrm{mg} . \mathrm{L}^{-1}$, sıcaklık: $25^{\circ} \mathrm{C}$, çalkalama hızı: $125 \mathrm{rpm}$, pomza miktarı: 7,5 g/100 mL, adsorpsiyon süresi: 1 saat)

\begin{tabular}{|c|c|}
\hline $\mathbf{p H}$ & Li Giderimi (\%) \\
\hline $\mathbf{3}$ & 2,08 \\
\hline $\mathbf{4 , 5}$ & 7,08 \\
\hline $\mathbf{8}$ & 7,79 \\
\hline $\mathbf{1 1 , 5}$ & 10,66 \\
\hline
\end{tabular}


Tablo 1'de görüldüğü üzere pH 11,5 değerine arttırılmasına rağmen Li giderimi \%10,66 olarak elde edilmiștir. Demir miktarının arttırılarak ya da farklı adsorbanlar ile hibrit denemelerinin sonraki çaılşmalarda planlanması düşünülmüştür.

\section{4. $\mathrm{MnO}_{2}$ kaplı pomzanın SEM ve FTIR analizi}

$\mathrm{MnO}_{2}$ kaplı pomzanın SEM analizi Şekil 3'de verilmiştir. Buna göre, $\mathrm{MnO}_{2}$ pomza üzerinde düzensiz bir şekilde kaplanmıştır. EDAX analizine göre ise $\mathrm{MnO}_{2}$ kaplı pomzada \%0,25 oranında Mn bulunmaktadır. Ayrıca $\mathrm{MnO}_{2}$ kaplı pomzada $\% 13,13 \mathrm{C}, \% 48,11 \mathrm{O}, \% 3,17 \mathrm{Na}, \% 6,54 \mathrm{Al}, \% 26,9 \mathrm{Si}, \% 1,61 \mathrm{~K}$ ve $\% 0,28 \mathrm{Ca}$ bulunmaktadır.
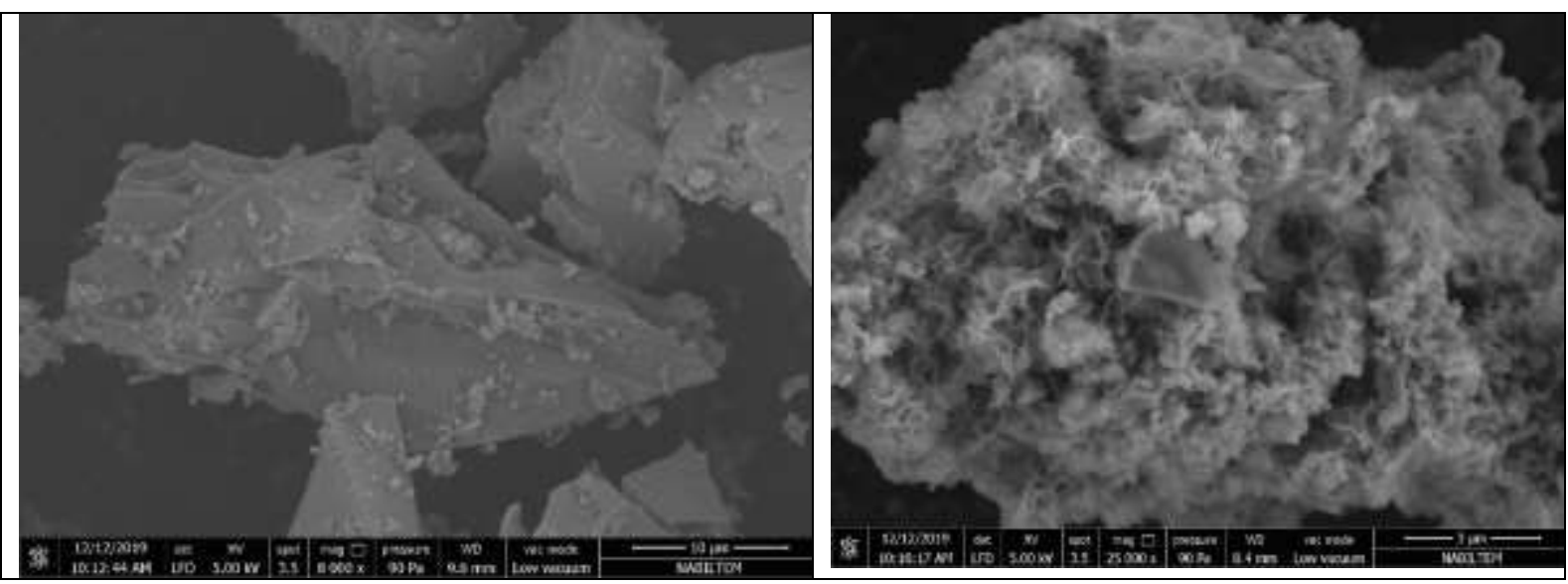

Şekil 3. $\mathrm{MnO}_{2}$ kaplı pomzanın SEM görüntüsü

$\mathrm{MnO}_{2}$ kaplı pomzanın FTIR analizi Şekil 4'de verilmiştir. Yaklaşı $1020 \mathrm{~cm}^{-1}$ ' de görülen absorpsiyon piki simetrik Si-O-Si gerilmesinden kaynaklanmaktadır [23-24]. Yine yaklaşık $767 \mathrm{~cm}^{-1}$ ve $449 \mathrm{~cm}^{-1}$, de görülen pikler de Si-O-Si veya Si-O-Al bandının gerilme titreşiminden kaynaklanmaktadır. $\mathrm{MnO}_{2} 1510,1280$ ve $1050 \mathrm{~cm}^{-1}$, de pik verirken, $\gamma-\mathrm{MnO}_{2} 1620 \mathrm{~cm}^{-1}$ 'de pik vermektedir [25].

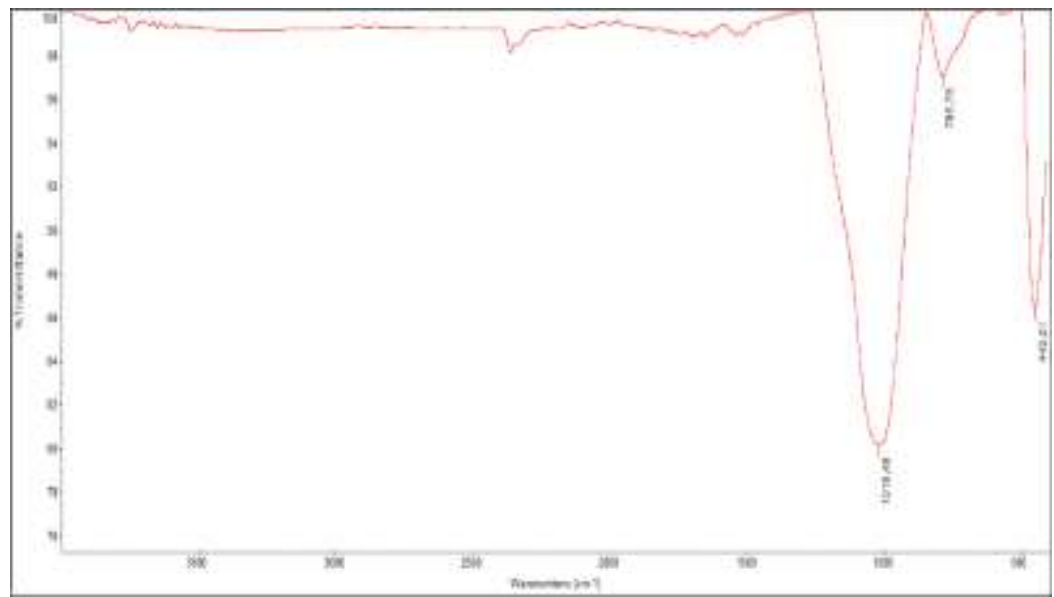

\section{Sonuçlar}

Şekil 4. $\mathrm{MnO}_{2}$ kaplı pomzanın FTIR analizi

Farklı pomza adsorbanları ile Li adsorpsiyonu çalışmaları gerçekleştirilen bu çalışmada, pomza ve manyetik demir kaplı pomza ile Li giderimi gözlenmemiştir. Ancak $\mathrm{Mn}$ kaplı ve $\mathrm{MnO}_{2}$ kaplı pomza adsorbanları ile yapılan çalışmalarda Li giderimi \%40 civarında gerçekleşmiş olup, her iki pomza karşılaştırıldığında en yüksek Li giderimi $\mathrm{MnO}_{2}$ kaplı pomza adsorbanı ile elde edilmiştir. Farklı adsorpsiyon sürelerinin Li giderimine etkisine bakıldı ğında 
ise ilk 60 dakikalık sürede adsorpsiyonun gerçekleşmiş ve 24 saat sonunda Li gideriminde herhangi bir artış gözlenmemiştir.

Farklı sabit sıcaklıklarda $\left(20^{\circ} \mathrm{C}\right.$ ve $\left.35^{\circ} \mathrm{C}\right)$ yapılan adsorpsiyon çalışmalarında $\mathrm{MnO}_{2}$ kaplı pomza adsorbanı için Li gideriminde sıcaklığın önemli bir etkisinin olmadığı görülmüştür.

$\mathrm{MnO}_{2}$ kaplı pomza adsorbanı ile Li gideriminde çözelti pH değerinin önemli bir etkiye sahip olduğu ve asidik koşullarda Li giderimi gözlenmez iken, $\mathrm{pH}$ 5'den pH 9'a kadar arttırıldığında Li gideriminin \%37,2 değerine arttığ1 tespit edilmiştir. Ancak pH 9 değerinden pH 11 değerine arttırıldığında Li gideriminde değişim gözlenmemiştir.

Sonuç olarak, Li geri kazanımı için $\mathrm{MnO}_{2}$ kaplı pomza malzemesi ile adsopsiyon yöntemi özellikle deniz suyundan tatlı su eldesi tesislerinde ön arıtma aşamasında uygulanan filtrasyon prosesine uygun bir alternatif oluşturmaktadir.

\section{Teșekkür}

Bu çalışma, Tekirdağ Namık Kemal Üniversitesi Bilimsel Araştırmalar Proje Ofisi tarafından destekli "Teknoloji Kritik Elementlerin Çevrede Etkileri ve Pomza Bazlı Yenilikçi Kompozitlerin Kullanıldı̆̆ Adsorpsiyon Metodu ile Atıksulardan Giderimi (Teknokompozit)" projesi (NKUBAP.06.GA.17.094) çerçevesinde gerçekleştirilmiştir. Yazarlar, deneysel çalışmalara katkılarından dolayı Burak Sarıgül ve Merve Duran’a, pomza temini için SOYLU LTD.A.Ş. AR-GE Müdürü Bülent Birden’e teşekkür ederler.

\section{Kaynaklar}

[1] Hoshino T. Preliminary studies of lithium recovery technology from seawater by electrodialysis using ionic liquid membrane. Desalination 2013; 317: 11-16.

[2] Çifçi Dİ, Adiloğlu S, Terzi S, Meriç S. Nadir toprak elementlerinden olan seryum ve lityumun sucul ve fitotoksik etkilerinin derlenmesi. Ömer Halisdemir Üniversitesi Mühendislik Bilimleri Dergisi 2019; 8(1): 9-22.

[3] Chitrakar R, Makita Y, Ooi K, Sonoda A. Lithium recovery from salt lake brine by H2TiO3. Dalton Trans 2014; 43: 89338939.

[4] Işık T, Baba A, Demir MM. Jeotermal ve tuzlu sistemlerden lityum kazanımı. Jesdergi 2018; 1: 16-18.

[5] Tian L, Ma W, Han M. Adsorption behavior of Li+ onto nano-lithium ion sieve from hybrid magnesium/lithium manganese oxide. Chem Eng J 2010; 156: 134-140.

[6] Wajima T, Munakata K, Uda T. Adsorption behavior of lithium from seawater using manganese oxide adsorbent. Plasma and Fusion Res 2012; 7(2405021): 1-4.

[7] Hawash S, Abd El Kader E, El Diwani G. Methodology for selective adsorption of lithium ions onto polymeric aluminium (III) hydroxide. J Am Sci 2010; 6(11): 301-309.

[8] Navarrete-Guijosa A, Navarrete-Casas R, Valenzuela-Calahorro C, López-González JD, García-Rodríguez A. Lithium adsorption by acid and sodium amberlite. J Colloid Interf Sci 2003; 264: 60-66.

[9] Seron A, Benaddi H, Beguin F, Frackowiak E, Bretelle JL, Thiry MC, Bandosz TJ, Jagiello J, Schwarz JA. Sorption and desorption of lithium ions from activated carbons. Carbon 1996; 34(4): 481-487.

[10] Liu L, Zhang H, Zhang Y, Cao D, Zhao X. Lithium extraction from seawater by manganese oxide ion sieveMnO2.0.5H2O. Colloids and Surfaces A: Physicochem Eng Aspects 2015; 468: 280-284.

[11] Ryu T, Shin J, Ryu J, Park I, Hong H, Kim B-G, Chung K-S. Preparation and Characterization of a Cylinder-Type Adsorbent for the Recovery of Lithium from Seawater. Mater Trans 2013; 54(6): 1029-1033.

[12] Zhang Q-H, Sun S, Li S, Jiang H, Yu J-G. Adsorption of lithium ions on novel nanocrystal MnO2. Chem Eng Sci 2007; 62: 4869-4874.

[13] Zhang Q-H, Li S-P, Sun S-Y, Yin X-S, Yu J-G. Lithium selective adsorption on 1-D MnO2 nanostructure ion-sieve. Adv Powder Technol 2009; 20: 432-437.

[14] Zhang Q-H, Li S-P, Sun S-Y, Yin X-S, Yu J-G. LiMn2O4 spinel direct synthesis and lithium ion selective adsorption. Chem Eng Sci 2010; 65(1): 169-173.

[15] Recepoğlu YK, Kabay N, Yılmaz-Ipek İ, Arda M, Yoshizuka K, Nishihama S, Yüksel M. Equilibrium and kinetic studies on lithium adsorption from geothermal water by $\lambda$-MnO2. Solvent Extr Ion Exc 2007; 35(3): 221-231.

[16] Zandevakili S, Ranjbar M, Ehteshamzadeh M. Recovery of lithium from Urmia Lake by a nanostructure MnO2 ion sieve. Hydrometallurgy 2014; 149: 148-152.

[17] Kamran U, Heo Y-J, Won Lee J, Park S-J. Chemically modified activated carbon decorated with MnO2 nanocomposites for improving lithium adsorption and recovery from aqueous media. J Alloy Compd 2019; 794: 425-434.

[18] Çifçi Dİ, Meriç S. A review on pumice for water and wastewater treatment. Desalin Water Treat 2016; 57(39): 1813118143

[19] Rusevova K, Kopinke F-D, Georgi A. Nano-sized magnetic iron oxides as catalysts for heterogeneous Fenton-like reactions-Influence of $\mathrm{Fe}(\mathrm{II}) / \mathrm{Fe}(\mathrm{III})$ ratio on catalytic performance. J Hazard Mater 2012; 241-242: 433-444.

[20] Miyai Y, Ooi K, Katoh S. Recovery of lithium from seawater using a new type of ion-sieve adsorbent based on MgMn2O4. Separ Sci Technol 1988; 23(1-3): 179-191. 
[21] Park HJ, Singhal N, Jho EH. Lithium sorption properties of HMnO in seawater and wastewater. Water Res 2015; 87: 320327.

[22] Günan Yücel H. Lityum(I) adsorpsiyonu için Pichia Stipitis mayası ile yeni bir hibrit adsorbent geliştirilmesi. MSc Hacettepe University, Ankara, Turkey, 2017.

[23] Sepehr MN, Amrane A, Karimaian KA, Zarrabi M, Ghaffar HR. Potential of waste pumice and surface modified pumice for hexavalent chromium removal: Characterization, equilibrium, thermodynamic and kinetic study, J Taiwan Inst Chem E 2014; 45: 635-647.

[24] Khorzughy SH, Eslamkish T, Ardejani FD, Heydartaemeh MR. Cadmium removal from aqueous solutions by pumice and nano-pumice. Korean J Chem Eng 2015; 32(1): 88-96.

[25] Saha S, Pal A. Microporous assembly of MnO2 nanosheets for malachite green degradation, Separ Purif Technol 2014; 134: $26-36$. 